\title{
ACE inhibitors - angiotensin II receptor antagonists: A useful combination therapy for ischemic heart disease
}

This article was published in the following Dove Press journal:

Open Access Emergency Medicine

I July 2010

Number of times this article has been viewed

\author{
T S Mohamed Saleem' \\ K Bharani' \\ K Gauthaman ${ }^{2}$ \\ 'Department of Pharmacology, \\ Annamacharya College of Pharmacy, \\ Rajampet-516126, Kadapa Dist, \\ Andhra Pradesh, India; ${ }^{2}$ Department \\ of Drug Technology, Higher Institute \\ of Medical Technology, Derna, Libya
}

Correspondence: T S Mohamed Saleem Department of Pharmacology, Annamacharya College of Pharmacy, New Boyanapalli, Rajampet-516I26, Andhrapradesh, India

Tel +9l-9701978543

Email saleemcology@gmail.com

\begin{abstract}
Morbidity and mortality from cardiovascular diseases are still high, even with the use of the best available therapies. There is mounting evidence that excessive renin-angiotensin system activation triggers much of the damaging and progressive nature of cardiovascular and kidney diseases through expression of angiotensin II. Moreover, angiotensin II play a major role in the development of end organ damage through a variety of inflammatory mechanisms. Today, angiotensins-converting enzyme (ACE) inhibitors and angiotensin II receptor antagonists have clearly demonstrated their efficacy in preventing target organ damage and in reducing cardiovascular morbidity and mortality in ischemic heart disease (IHD). Moreover, the development of angiotensin II receptor antagonists has enabled a large gain in tolerability and safety. Several clinical trials have firmly established that these drugs act on the renin-angiotensin system, reducing the incidence of coronary events with monotherapy and combination therapy. In this review we summarize the role mono- and combined therapy of ACE inhibitors and angiotensin II receptor antagonists play in ischemic heart disease. In this respect the review will improve ideas for developing new formulations with combinations of these drugs in the future.
\end{abstract}

Keywords: angiotensin receptor blockers, renin angiotensin system, angiotensin II

\section{Introduction}

Cardiovascular research has the ultimate goal of enhancing the ability to understand and ameliorate cardiovascular disease. Coronary heart disease is the leading cause of death world wide, and 3.8 million men and 3.4 million women die of the disease each year. After an acute myocardial infarction, the use of thrombolytic therapy or primary percutaneous coronary intervention (PCI) is the most effective strategy for reducing the size of myocardial infarct and improving the clinical outcome. The process of restoring blood flow to the ischemic myocardium, however, can induce injury. This phenomenon, termed myocardial reperfusion injury, can paradoxically reduce the beneficial effects of myocardial reperfusion. The most important development in the treatment of myocardial infarction and heart failure, is the emergence of agents which are used to limit cardiac remodeling and dysfunction via neurohumoral blockade. ${ }^{1}$ Myocardial ischemia and subsequent reperfusion of the ischemic tissue, has been associated with various types of injury, including lethal reperfusion injury, myocardial stunning, and cardiac arrhythmias. Preventing or reducing these myocardial ischemia/reperfusion injuries could improve the beneficial effects of therapies, (such as coronary artery bypass grafting, angioplasty, and thrombolytic agents), intended to cause reperfusion of ischemic tissue. ${ }^{2}$ During ischemia/reperfusion, cells may undergo either the process 
of necrosis or apoptosis. What determines whether a cell initiates apoptosis, necrosis or neither process is presently unclear. However, an agent to minimize the amount of viable cells that undergo reperfusion-induced death and decrease ventricular tachycardia when coronary blood flow is restored, may reduce the extent of sudden death, heart failure and ventricular remodeling postmyocardial infarction. Currently, no agent is universally accepted for the treatment of reperfusion injury. ${ }^{3}$

\section{Renin-angiotensin system}

Cardiovascular diseases (CVD) such as ischemic heart disease and atherosclerosis are characterized by endothelial dysfunction, a pro-inflammatory state and often also by extensive vascular remodeling. The renin-angiotensin system (RAS) plays a key role in the pathophysiology of CVD and organ damage across the cardiovascular continuum. It controls cardiovascular, renal, and adrenal function by regulating body fluids, electrolyte balance, and arterial pressure. Renin, released in the kidney in response to a reduction in arterial pressure, converts angiotensinogen into angiotensin I (Ang I), which is then converted to angiotensin II (Ang II) by angiotensin-converting enzyme (ACE). Ang II, the main peptide of the RAS, participates in the pathogenesis of several cardiovascular diseases. Ang II is a pleiotropic vasoactive peptide that binds to two specific receptor subtypes, $\mathrm{AT}_{1}$ and $\mathrm{AT}_{2}$. $\mathrm{AT}_{1}$ predominates in vascular tissues and contributes to chronic diseases, such as hypertension, atherosclerosis, cardiac hypertrophy, and renal injury by promoting cell growth, inflammatory responses, and fibrosis. The molecular mechanisms elicited by $\mathrm{AT}_{1}$ activation are common to classical cytokines. The $\mathrm{AT}_{1}$ receptor is linked to calcium mobilization, production of arachidonic acid metabolites, and activation of several kinases, such as protein kinase C (PKC), phosphotyrosine kinases (PTK), mitogen-activating protein kinases (MAPK), and c-Jun amino terminal kinases (JAK). $\mathrm{AT}_{2}$ expression can be modulated by pathologic states associated with tissue remodeling or inflammation. $\mathrm{AT}_{2}$ causes cardioprotection, vasodilation, renal natriuresis, cell growth inhibition, and renal inflammatory cell infiltration. $\mathrm{AT}_{2}$ receptor activation leads to stimulation of the kinin/nitric oxide/ cGMP system, phospholipase $\mathrm{A}_{2}$, prostaglandin metabolism, and protein tyrosine or serine/threonine phosphatases in a Gi protein-dependent manner. Although there is much data related to Ang II signaling, our understanding of AT receptor signaling mechanisms remains incomplete..$^{4-7}$

Ang II promotes endothelial dysfunction, vascular inflammation and remodeling, at least in part, by inducing an excessive vascular oxidative stress following upregulation of NADPH oxidase. ${ }^{8,9}$ Reactive oxygen species (ROS) may act as signal transduction messengers for several important transcription factors, including NF-kB and AP-1. Ang II activates NF- $\mathrm{B}$, the key nuclear transcription factor in inflammatory and fibrotic diseases. Activation of NF- $\kappa \mathrm{B}$ by Ang II may stimulate transcription of numerous inflammatory genes, including monocyte chemoattractant protein-1 (MCP-1), RANTES (regulated on active normal T cell expressed and secreted) and interleukin (IL)-6, tumor necrosis factor- $\alpha$ (TNF- $\alpha$ ) and transforming growth factor (TGF- $\beta$ ). MCP-1 is one of the most important chemokines in Ang II induced inflammatory responses. ${ }^{10}$ In addition Ang II stimulates circulating leukocytes and endothelial cells, thereby promoting inflammation and interstitial extracellular matrix accumulation. ${ }^{7}$ Ang II activation may involve ROS activation of Akt, NF-kB activates numerous genes, including interleukin (IL)-1, IL-6, IL-8, interferon- $\gamma$, TNF- $\alpha$, intercellular adhesion molecule-1 (ICAM-1), VCAM-1, and the chemokine MCP-1. ${ }^{11}$

\section{Methods of RAS blockade: ACE inhibitors and ARBs}

ACE inhibitors (lisinopril, trandolapril, enalapril, benazepril, fosinopril, perindopril, quinapril and captopril) decrease levels of circulating Ang II by inhibiting ACE. ${ }^{5}$ However, ACE inhibitors do not fully prevent conversion of Ang I to Ang II because other enzymes (eg, chymase and cathepsin G) are capable of synthesizing Ang II. ${ }^{12,13}$ Angiotensin II receptor blockers (ARBs) (eg, valsartan, losartan, candesartan, telmisartan, olmesartan, and irbesartan) act by selectively blocking the $\mathrm{AT}_{1}$ receptor, thereby directly blocking the vasoconstrictor and growth effects of Ang II. ${ }^{13}$ Selective blockade of the $\mathrm{AT}_{1}$ receptor has additional cardiovascular benefits resulting in vasodilation, growth inhibition, and nitric oxide and bradykinin production. ${ }^{12-14}$ Figure 1 shows the complete process of RAS and the different sites of potential pharmacological interruption.

The beneficial effects of $\mathrm{AT}_{1}$ antagonists in the treatment of cardiovascular diseases are due to the following: firstly, the selective $\mathrm{AT}_{1}$ blockade targets the final common pathway for all major detrimental cardiovascular actions of Ang II. Secondly, circulating Ang II levels are increased during AT 1 blockade, and free Ang II can bind to $\mathrm{AT}_{2}$ receptors. The $\mathrm{AT}_{2}$ stimulation counteracts the negative consequences of Ang II, presenting favorable effects on tissue growth and repair processes, potentially providing additional endorgan protection. The other blockers of the RAS are the ACE inhibitors that 


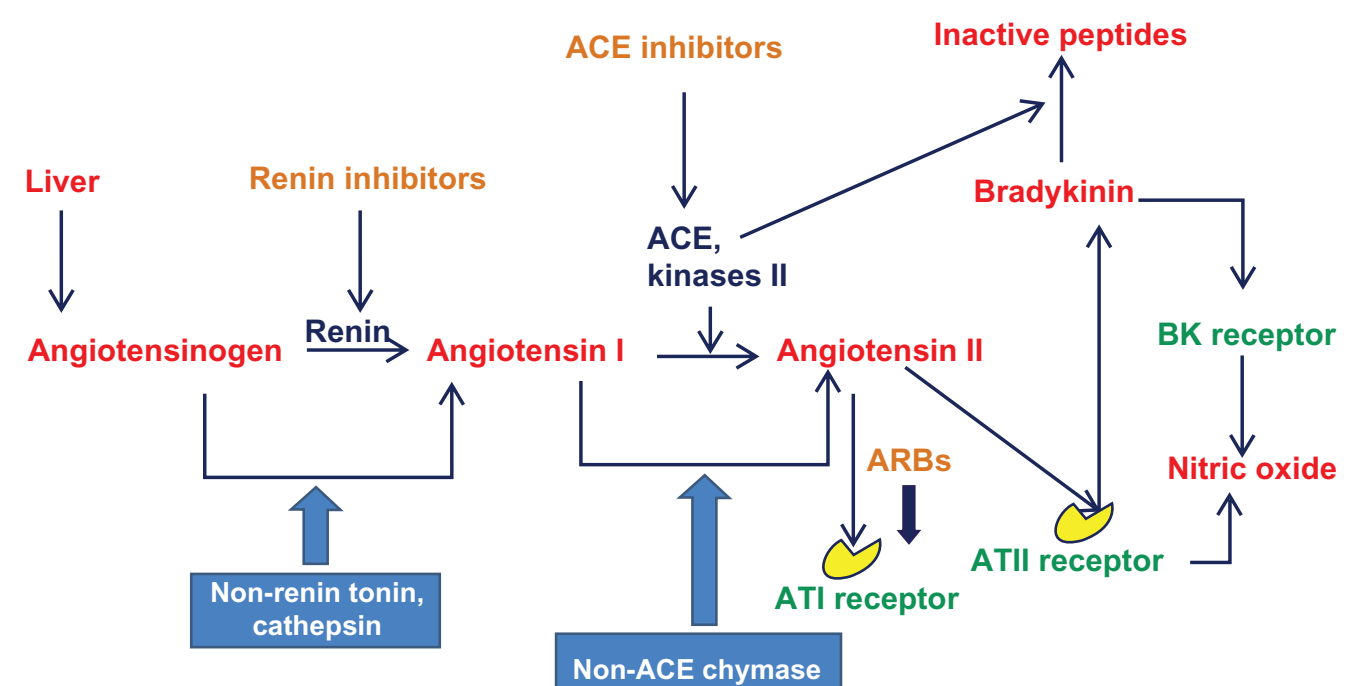

Figure I Schematic representation of the renin angiotensin system and the different sites of potential pharmacological interruption.

interrupt this system by preventing the conversion of Ang I to Ang II, therefore decreasing local Ang II generation. They also increase plasma levels of bradykinin, which possesses vasodilator and tissue-protective properties. ${ }^{4,5}$

\section{RAS blockers in clinical use ACE inhibitors}

ACE inhibitors are widely used in the treatment of hypertension, congestive heart failure (CHF) and post ischemic myocardial dysfunction. Long term administration of ACE inhibitors has been reported to enhance the endogenous antioxidant substances. ${ }^{15}$ In addition to reducing levels of Ang II and increasing bradykinin, emerging evidence suggest that ACE inhibitors have important implications for vascular oxidative stress. On the basis of a link between ACE action and vascular $\mathrm{NAD}(\mathrm{P}) \mathrm{H}$ oxidase activity, $\mathrm{ACE}$ inhibitors represent a novel antioxidant strategy that targets oxidative stress at its source. ${ }^{16}$

ACE inhibitors have been available in clinical practice for almost 20 years. Numerous clinical trials have demonstrated that ACE inhibitors reduce cardiovascular morbidity and/or mortality in patients with hypertension, congestive heart failure, myocardial infarction, type 1 and 2 diabetes and chronic renal failure. The results of the recent Heart Outcomes Prevention Evaluation (HOPE) trial have even demonstrated that lisinopril could reduce by $22 \%$ the incidence of cardiovascular complications (stroke, myocardial and cardiovascular deaths) in patients with a high cardiovascular risk who are not necessarily hypertensive and decrease the incidence of new cases of diabetes. However, some large clinical trials are still underway to evaluate the potential benefits of ACE inhibitors in other clinical conditions such as the secondary prevention of coronary heart disease or the prevention of stroke. Thus, the results of the Perindopril Protection against Recurrent Stroke Study (PROGRESS), a study that compares the efficacy of an ACE-inhibitor-based therapy in the secondary prevention of stroke have been published. ${ }^{17}$ More recently, the results of the EUROPA (EUropean trial on Reduction Of cardiac events with Perindorpil in patients with stable coronary Artery disease) trial have demonstrated that treatment with the ACE inhibitor perindopril reduces the cardiovascular risk in a low risk population with stable coronary heart disease and no apparent heart failure. ${ }^{18}$

ACE inhibitors are considered to affect heart failure following myocardial infarction as a consequence of a combination of neurohormonal, hemodynamic, left ventricular (LV) structural remodeling and other effects. ${ }^{19}$ In patients treated with captopril, ischemia-related events were reduced during the first 3 to 12 months after myocardial infarction (MI) but there was rebound phenomenon after the withdrawal of treatment. ACE inhibitors containing sulfhydryl groups may have additional beneficial effects in scavenging free radicals and reducing reperfusion damage. ${ }^{20}$ Based on the clinical trials study, ACE inhibitors can be utilized in hemodynamically stable patients within the first 24 hours after acute MI, asymptomatic LV dysfunction after MI, and CHF. ${ }^{21}$ There were no significant benefits when the ACE inhibitor was given within the first 3 weeks after MI. Captopril therapy in chronically infarcted rats improved cardiac function when therapy was started after completion of the healing process. Recent studies revealed the beneficial effects of captopril and 
imidapril on cardiac dysfunction when these ACE inhibitors were administered within 1 to 3 hours after the induction of $\mathrm{MI}$ in rats. ${ }^{22,23}$ It is pointed out that the major side effects of ACE are cough, renal dysfunction and first dose hypotension. These effects are due to ACE inhibitors-induced bradykinin formation. ${ }^{24}$

\section{Angiotensin II receptor blockers}

It is now 10 years from the time since the first ARBs were introduced for clinical use. Today, seven orally active ARBs have been registered by the US FDA. ARBs effectively lower blood pressure in hypertensive patients, without affecting heart rate, regardless of gender and age. The antihypertensive efficacy of ARBs is comparable with that of other first-line antihypertensive agents. The major advantage of Ang II receptor antagonists is their excellent tolerability profile. $^{25}$

Three large trials, of which two have been completed, have been designed to assess the effects of ARBs on morbidity and mortality in hypertensive patients. The LIFE trial (Losartan Intervention For Endpoint Reduction in Hypertension) compared a losartan and an atenolol-based regimen in 9,193 hypertensive patients with documented left ventricular hypertrophy Several short-term clinical studies conducted in patients with symptomatic congestive heart failure without ACE inhibitors have demonstrated the Ang II receptor antagonists exert beneficial hemodynamic and neurohormonal effects in heart failure. ARBs have no influence on glomerular filtration rate, but they increase renal blood flow. In diabetic and nondiabetic patients, Ang II antagonists have regularly been found to lower urinary albumin excretion. ${ }^{27,28}$ Some ARBs including valsartan, candesartan cilexetil, irbesartan, telmisartan and losartan, are currently used for the treatment of patients with hypertension. ${ }^{29}$ It has been reported that ARBs are not effective as ACE inhibitors in preventing cardiac remodeling, but $\mathrm{AT}_{1}$ receptor antagonists do have the same effect in attenuating cardiac hypertrophy and long-term mortality as compared to ACE inhibitors. ${ }^{30}$ In normal rat cardiomyocytes, losartan was shown to block the increase of $\mathrm{Ca}^{2+}$ and cell beating stimulated by Ang II. ${ }^{31}$ When losartan was administered locally in the coronary circulation of dogs, there was a greater increase in coronary cross-section area and coronary blood flow, than the results observed in the ACE inhibitor (enalapril) trial. ${ }^{32}$ It has been suggested that nitric oxide released from endothelial cells of epicardial vessels may be involved in this vasodilatory effect of losartan. ${ }^{33-35}$

\section{ACE inhibitors and the ischemic myocardium}

ACE inhibitors have been shown to prolong the survival of patients after cardiac infarction. Various experiments on the cardioprotective effect of ACE inhibitors in the isolated hearts of dogs, guinea pig, and rats, revealed that the kinin B2 receptor via activation of the endothelial nitric oxide (NO) synthase is involved in the protection against ischemic reperfusion injury and reperfusion induced arrhythmia. ACE inhibitors have been shown to reduce myocardial ischemia/reperfusion injury. This protective effect is produced through an action to preserve the peptide bradykinin from rapid degradation, rather than by decreasing production of Ang II. The ACE inhibitors reduced myocardial ischemia/reperfusion injury in an in vivo model using 30 minutes of regional ischemia and 2 hours of reperfusion. ${ }^{36,37}$

The reasons for the lack of effect of ACE inhibitors in some studies are not clear. Some studies have showed that captopril but not enalapril was protective in the isolated rat heart and attenuated lipid peroxidation. Indeed, it has been proposed that ACE inhibitors, such as captopril, that possess sulfhydryl moieties, are able to act as scavengers or reactive oxygen species and as a consequence are protective when administered alone. ${ }^{8,38}$

The question of whether ACE inhibitors are independently cytoprotective in experimental acute myocardial ischemia without preconditioning remains unanswered. However, the recent HOPE trial demonstrated that lisinopril reduced risk of death in patients with coronary artery disease, ${ }^{39}$ an effect that appears to be unrelated to blood pressure reduction alone. Recently, large clinical trials have been designed to study whether the preventive treatment with ACE-inhibitors may also reduce the rate of ischemic events. One of these is the PEACE (Prevention of Events with Angiotensin-Converting Enzyme inhibitiors) study, which tests the effect of trandolapril. The molecular mechanisms by which ACE-inhibitors could play a preventive role in ischemic events are still unknown. Besides their anti-proliferative and anti-atherogenic activities, ACEinhibitors are now considered as myocardial and vascular 'protective' agents. ACE-inhibitors, in addition to their inhibitory activity on Ang II production, increase the local availability of bradykinin, which plays an important role in the regulation of the endothelial constitutive nitric oxide synthase (eNOS) the enzyme responsible for nitric oxide (NO) production. NO, in turn, could have cardioprotective effects since it reduces cardiac function and the rate of energy expenditure. ${ }^{40}$ 


\section{ACE inhibitors - angiotensin II receptor blockers: a useful combination?}

Hypertension is usually associated with concomitant diseases such as congestive heart failure, diabetes, MI, diabetic nephropathy, and IHD. In some cases, the concomitant diseases are actually due to long-standing hypertension. ${ }^{41}$ Two or more drugs are needed to control blood pressure in the majority of patients with hypertension. The most commonly used combinations include a diuretic; however, results of two large, controlled trials show that better cardiovascular protection is provided by a combination of a renin-angiotensin inhibitor and a long-acting calcium-channel blocker (CCB) than combinations that include a diuretic. There are a number of reasons why combination therapy is becoming more widely available and prescribed. Firstly, data from multiple trials indicate that two or more drugs are needed to lower blood pressure to the target of $<140 / 90 \mathrm{mmHg}$ for patients with uncomplicated hyper tension, and $<130 / 80 \mathrm{mmHg}$ for the majority of the hypertensive population who have concomitant diseases, including diabetes, chronic kidney disease, or IHD. Secondly, the combination of two drugs in one tablet improves adherence to therapy and a combination will cost less than separate prescriptions. Thirdly, the most widely prescribed CCB in the US, amlodipine, is now generic and therefore, available as an inexpensive and highly effective partner to both ACE inhibitors and ARBs. Two ARB and amlodipine combinations have been marketed and many more are near approval. ${ }^{42,43}$

A recent review reported a beneficial effect of combination therapy: for example the addition of losartan with trandolapril proved to be better at reducing the primary end point. A second study has compared irbesartan vs amlodipine vs placebo. The irbesartan was significantly better that the placebo group as well as amlodipine in reducing target damage. A third study has compared losartan vs atenolol. The overall relative risk reduction was better in the losartan group than the atenolol group. ${ }^{41}$ The latest trial comparing two different combinations of antihypertensive medication is the ACCOMPLISH (Avoiding Cardiovascular Events through Combination Therapy in Patients Living with Systolic Hypertension) was designed to compare the generally recommended combination of an ACE inhibitor with a diuretic, with the combination of an ACE inhibitor and a CCB. Only $32 \%$ of patients in each group needed additional medication to reduce their blood pressure to target. The trial was stopped early (mean follow-up 36 months) because of the significantly higher morbidity and mortality in the ACE inhibitor plus diuretic group. Overall, patients who received the ACE inhibitor plus the CCB had a $20 \%$ reduced relative risk for the primary end point. Results from the ACCOMPLISH study suggest that patients receiving an ACE inhibitor plus a CCB do better than patients receiving an ACE inhibitor and a diuretic. ${ }^{42-44}$ The major outcome trials suggests that there are some agents that do have protective effects on target organs. In general, these agents tend to be ARBs or combination of ARBs plus ACE inhibitors. ${ }^{41}$ In order to answer the question of whether the combination of ACE inhibitors and ARBs will provide benefits over using ACE inhibitors or ARBs alone, both experimental animal models of CHF and clinical studies were designed with a combination of ACE inhibitor and ARB therapy. The preliminary results indicate that the agents may be additive. ${ }^{45,46}$

In salt-depleted normotensive volunteers, the combined administration of a standard single oral dose of an ACE inhibitor (captopril $50 \mathrm{mg}$ ) and an Ang II antagonist (losartan $50 \mathrm{mg}$ ) has been shown to induce an additional blood pressure reduction characterized mainly by a longer duration, and to have a major additive effect on the reactive rise in plasma renin activity. ${ }^{47}$ More recently, the CALM and the COOPERATE studies have shown that combining an ARB (candesartan in CALM and losartan in COOPERATE) with an ACE inhibitor produces a greater decrease in urinary protein excretion in patients with type 2 diabetes (CALM) and in patients with non-diabetic proteinuria (COOPERATE) ${ }^{48,49}$ Based on these results, it is proposed that a combination of an $\mathrm{ACE}$ inhibitor with an $\mathrm{ARB}$ could achieve a more complete blockade of the RAS than either therapeutic approach alone. However, not all antagonists provide the same degree of Ang II receptor antagonism, at least at the recommended starting dose, and a greater reactive rise in plasma Ang II levels can be obtained with $150 \mathrm{mg}$ irbesartan than with $50 \mathrm{mg}$ losartan. ${ }^{50}$ However, the use is lacking in acute myocardial ischemia/reperfusion. ${ }^{51}$

ACE inhibition alone is not sufficient to suppress RAS activity due to counter-regulatory pathways such as an increase in alternatively-formed Ang II and plasma renin activity (PRA). The same is true for $\mathrm{AT}_{1}$-receptor inhibition with $\mathrm{ARBs}$, which leaves the $\mathrm{AT}_{2}$-receptor open for stimulation by alternatively formed Ang II. In consequence, the combination of ARBs and ACE-inhibitors might produce a more complete inhibition of the system and enhance bradykinin accumulation resulting in increased endothelial $\mathrm{NO}$ production. ${ }^{51,52}$

A recent study reported that ACE inhibitors or ARBs are associated with low incidence of postoperative randomized trial of 4016 patients with blood pressure (BP) $<160 / 100 \mathrm{mmHg}$, had been treated with ACE inhibitors for $>3$ months. The patients discontinued ACE inhibitors 
and switched to losartan. After 1 month the BP decreased to 7.7/4.7 $\mathrm{mmHg}$, and after 1 year to $13.8 / 8.7 \mathrm{mmHg}$. CORD B compared ramipril and losartan in 3813 patients with hypertension who were not being treated with an ACEI or ARB. The patients were randomised to ramipril $(n=1926)$ or losartan $(\mathrm{n}=1887)$. After 1 year the BP decreased in the ramipril group to $21.8 / 13.7 \mathrm{mmHg}$ and in the losartan group to $22.0 / 13.3$ $\mathrm{mmHg}$. No significant differences or adverse effects were found. Dry cough was more frequent after ramipril. ${ }^{53-55}$

Several large, randomized, multicenter studies demonstrated that ACE inhibitors and ARBs are able to retard renal disease progression. ${ }^{56} \mathrm{~A}$ review demonstrates that significant clinical benefit can be derived from ACE inhibitors and ARBs even when added to other currently recommended treatment strategies in post-MI patients. The favorable effects of RAS inhibition on important prognostic markers such as atrial fibrillation, renal function, and diabetes have recently been unraveled. ${ }^{57}$

In diabetic patients $\mathrm{ACE}$ inhibitors and ARBs both effectively lower blood pressure, particularly in combination with low-dose thiazide diuretics, and may be considered first line therapies in the treatment of diabetic hypertension. Blockade of the RAS with these agents appears to play an important role not only in protecting from renal disease, but may also help to reduce morbidity and mortality from certain vascular diseases in diabetic patients. ${ }^{58}$ In patients with acute high-risk myocardial infarction, the Valsartan in Acute Myocardial Infarction Trial (VALIANT) trial has established that the ARB was as effective as an ACE inhibitor following myocardial infarction. These studies have thus provided clinicians with alternatives to ACE inhibitors in these important clinical syndromes. ${ }^{59}$ ARBs have been shown to be selective PPAR- $f$ Á modulators. The therapeutic role of RAS Blockade in CHF with myocardial hypertrophy and heart failure patients, as shown in LIFE, Candesartan in Heart failure: Assessment of Reduction in Mortality and morbidity (CHARM) and Valsartan Antihypertensive Long-term Use Evaluation (VALUE) studies could partly be attributed to this pathway. ${ }^{52,60}$

Left ventricular hypertrophy (LVH) is a crucial prognostic factor for morbidity and mortality in ischemic heart disease. Experimental data suggest that RAS blockade should reverse or inhibit the development of maladaptive LVH. Many studies, such as HOPE, ${ }^{61}$ LIFE $^{62}$ and Optimal Trial in Myocardial Infarction with losartan (OPTIMAAL), ${ }^{63}$ have demonstrated significant benefits of ACE inhibitors or ARB monotherapy on left ventricular remodeling. ${ }^{64}$ For instance, when data from the HOPE ${ }^{65}$ the European trial on Reduction of Car- diac Events with Perindopril (EUROPA), ${ }^{66}$ the PEACE $^{67}$ and Quinapril Ischaemic Event Trial (QUIET) ${ }^{68}$ studies were pooled, the authors of the meta-analysis showed, in a total of 31,555 patients, ACE inhibitor therapy produced $14 \%$ reductions in all-cause mortality and myocardial infarction, a $23 \%$ reduction in stroke, and a $7 \%$ reduction in revascularization procedures compared with placebo. ${ }^{52}$ Recent studies have suggested that dual RAS blockade may be superior to monotherapy with losartan or ramipril with respect to cardiac remodeling in hypertensive patients. However, the VALIANT trial, comparing potential benefits of ACE inhibitors and ARB combination therapy in patients with reduced systolic function after myocardial infarction, showed no difference in therapy with captopril. ${ }^{52,69}$

Several major trials, such as the Cooperative North Scandinavian Enalapril Survival Study (CONSENSUS), ${ }^{70}$ have clearly shown that ACE inhibitors reduce cardiovascular mortality and morbidity. The Evaluation of Losartan in the Elderly (ELITE) II study, for example, compared the effects of losartan and captopril in 3,152 patients with heart failure and decreased left ventricular ejection fraction. Furthermore, the Randomized Evaluation of Strategies for Left Ventricular Dysfunction (RESOLVD) study also indicated that combining an ACE inhibitor with an ARB decreased blood pressure. ${ }^{52,71-72}$

An optimal dosage of the three major neuroendocrine antagonists, beta-blockers, ACE inhibitors and/or AT 1 -receptor blockers, contributes to improve the prognosis of $\mathrm{CHF}$ patients. ${ }^{52,73} \mathrm{~A}$ meta-analysis of the effect of a combination of ACE inhibitors and ARBs vs ACE inhibitors alone on blood pressure found that combination therapy with an ACE inhibitor and an ARB reduced ambulatory blood pressure by 4.7/3.0 $\mathrm{mmHg}$ overall compared with $3.8 / 2.9 \mathrm{mmHg}$ for ACE inhibitor monotherapy and clinic blood pressure by $3.8 / 2.7 \mathrm{mmHg}$ compared with $3.7 / 2.3 \mathrm{mmHg}{ }^{74,75}$ Combination therapy with an ACE inhibitor and an ARB is not beneficial in all situations, for example acute myocardial infarction with subsequent heart failure, as studied in VALIANT. The (ONTARGET) trial compares the relative benefits of ACE inhibitors, ARBs or both in the prevention of $\mathrm{CHF}$ in patients at risk for this condition. ${ }^{52}$

It is clear that further, large-scale, controlled clinical studies are required to establish the relative advantages of combination therapy with ARBs and ACE inhibitors and monotherapy with either treatment alone. One such trial is the [ONgoing Telmisartan Alone and in combination with Ramipril Global Endpoint Trial] ONTARGET, which is investigating the benefits of combination treatment with telmisartan and ramipril. ONTARGET itself and its sister trial Telm- 
isartan Randomized AssessmeNt Study in aCE-iNtolerant subjects with cardiovascular Disease (TRANSCEND) form the largest study program to date comparing ARBs and ACE inhibitors and therapy in high-risk patients with controlled blood pressure (the ONTARGET program). ONTARGET itself, involving more than 25,500 patients from 40 countries worldwide, will compare the effect of ACE inhibition with high-dose ramipril with that of the ARB telmisartan and a combination of the two on a composite of cardiovascular death. ${ }^{75,76}$

In an animal study of heart failure produced by rapid atrial pacing, the ACE inhibitor benazipril resulted in improvement in myocyte beta-adrenergic response. The combination of benazipril and valsartan resulted in changes in the parameters that were greater than those obtained with ACE inhibition alone. In rats combination therapy has been shown to reduce the deleterious effects. ${ }^{77}$

Since Ang II can be produced by non-ACE pathways unaffected by ACE inhibitors and furthermore, ACE inhibitor treatment results in upregulation of the $\mathrm{AT}_{1}$-receptor, combination therapy may be necessary to achieve a more complete blockade of the RAS than with ACE inhibitors alone. ${ }^{77}$ In chronic congestive heart failure, ValHeFT and CHARM-ADDED showed beneficial effects of dual RAS blockade. ${ }^{52,78}$ The beneficial action of RAS blockade on cardiac function in CHF are considered to be due to its ability to limit infarct size, enhance scar formation and reduce infarct expansion to decrease ventricular wall stress and prevent the ventricular remodeling after MI. ${ }^{79}$ The complementary mechanisms of action of these 2 drug classes also create a strong rationale for combination therapy in high-risk patients because Ang II can be produced by nonACE pathways that are unaffected by ACE inhibitors, and furthermore, ACE inhibitor treatment results in upregulation of the $\mathrm{AT}_{1}$ receptor. Thus, combination therapy with $\mathrm{ARBs}$ and ACE inhibitors may be necessary to achieve more complete RAS blockade than can be achieved with either agent alone. Adequately powered comparative trials are needed to define the relative benefits of $\mathrm{ARBs}$ and $\mathrm{ACE}$ inhibition. ${ }^{75}$

\section{Conclusion}

This review article points to a need for more in depth understanding of the role of ACE inhibitors and ARBs in the cardiovascular system, especially in ischemic heart disease. Both ACE inhibitors and ARBs interfere with the activity of the RAS in a different way. Theoretically, one might expect beneficial effects when they are used in combination, as a more complete suppression of the RAS can be achieved. Several controlled trials have demonstrated that combination therapy could have additional benefits in hypertensive patients, in chronic heart failure patients, and in both diabetic and nondiabetic nephropathy patients. However, the clinical benefit was not always as pronounced as expected and not every patient will benefit from dual blockade of the RAS. There is some evidence of a less pronounced effect of combination therapy when a full dose of the ACE-inhibitor is given. Several studies have now demonstrated the physiological and pathological functions of Ang II in cardiovascular diseases. Blockade of RAS with effective drugs will provide protection against organ damage through inhibition of Ang II production. However, it is well known that ACE-inhibitors cannot completely suppress the formation of Ang II, in particular, when the RAS is activated. Indeed, clinical trials indicated that add-on therapy with an ARB was especially of use when the RAS remained activated despite full-dose ACE-inhibitor treatment. In summary, combination of a full-dose ACE-inhibitor and an ARB can be a rational choice in selected patients. However the mechanism of action of combined therapy of ACE-inhibitor and an ARB remains unproven. More research is required (in both animals and humans) with combined therapy.

\section{Acknowledgment and disclosure}

This study was supported by grant in aid for research promotion scheme from the AICTE, New Delhi, India. The authors declare no conflicts of interest.

\section{References}

1. Yellon DM, Hausenloy DJ. Myocardial reperfusion injury. NEngl J Med. 2007;357:1121-1135.

2. Hearse DJ, Bolli R. Reperfusion induced injury: manifestations, mechanisms, and clinical relevance. Cardiovasc Res. 1992;26: 101-108.

3. Gross ER, Gross GJ. Pharmacologic therapeutics for cardiac reperfusion injury. Expert Opin Emerg Drugs. 2007;12:367-388.

4. Maggioni AP. Efficacy of angiotensin receptor blockers in cardiovascular disease. Cardiovasc Drugs Ther. 2006;20:295-308.

5. Ruiz-Ortega M, Ruperez M, Esteban V, Egido J. Molecular Mechanisms of Angiotensin II induced Vascular Injury. Current Hypertension Reports. 2003;5:73-79.

6. Xu J, Carretero OA, Liu Y, et al. Role of AT2 receptors in the cardioprotective effect of AT1 antagonists in mice. Hypertension. 2002;40: 244-250.

7. Nian M, Lee P, Khaper N, Liu P. Inflammatory cytokines and postmyocardial infarction remodeling. Circ Res. 2004;94:1543-1553.

8. Walter A, Etienne-Selloum N, Sarr M, Kane MO, Beretz A, Schini-Kerth VB. Angiotensin II induces the vascular expression of VEGF and MMP-2 in vivo: preventive effect of red wine polyphenols. J Vasc Res. 2008;45:386-394.

9. Tummala PE, Chen X, Sundell CL, et al. Angiotensin II induces vascular cell adhesion molecule-1 expression in rat vasculature: A potential link between the renin-angiotensin aystem and atherosclerosis. Circulation. 1999;100:1223-1229.

10. Zhuo JL. Monocyte chemoattractant protein-1: a key mediator of angiotensin II-induced target organ damage in hypertensive heart disease? J Hypertens. 2004;22:451-454. 
11. Muller DN, Mervaala EM, Schmidt F, et al. Effect of bosentan on NF-kappaB, inflammation, and tissue factor in angiotensin II-induced end-organ damage. Hypertension. 2000;36:282-290.

12. Weber MA. The angiotensin II receptor blockers: opportunities across the spectrum of cardiovascular disease. Rev Cardivasc Med. 2002;3: 183-191.

13. Schmieder RE. Mechanisms for the clinical benefits of angiotensin II receptor blockers. Am J Hypertens. 2005;18:720-730.

14. Martin J, Krum H. Role of valsartan and other Angiotensin receptor blocking agents in the management of cardiovascular disease. Pharmacol Res. 2002;46:203-212.

15. De Cavanagh EM, Fraga CS, Ferder L, Inserra F. Enalapril and captopril enhances antioxidant defences in mouse tissues. Am J Physiol. 1997;272:R514-R518.

16. Munzel T, Keaney JF. Are ACE inhibitors a "magic bullet" against oxidative stress? Circulation. 2001;104:1571-1574.

17. Meier P, Maillard M, Burnier M. The future of angiotensin II inhibition in cardiovascular medicine. Curr Drug Targets Cardio Haematol Disord. 2005;5:15-30.

18. Fox KM. The EURopean trial On reduction of cardiac events with Perindopril in stable coronary Artery disease Investigators, Efficacy of perindopril in reduction of cardiovascular events among patients with stable coronary artery disease: randomized, doubleblind, placebo-controlled, multicentre trial (the EUROPA study). Lancet. 2003;362:782-788.

19. Codi RJ. ACE inhibitors: myocardial infarction and conjestive heart failure. Am Fam Physician. 1995;52:1801-1806.

20. Westlin W, Mullane K. Does captopril attenuate reperfusion-induced myocardial dysfunction by scavenging free radicals? Circulation. 1988; 77:130-139.

21. Ambrosioni E, Borchi C, Magnani B. The effect of the angiotensinconverting enzyme inhibitor zofenopril on mortality and morbidity after anterior myocardial infarction. The Survival of Myocardial Infarction Long-Term Evaluation (SMILE) study investigators. $N$ Engl $J$ Med. 1995;332:80-85.

22. Shao Q, Ren B, Zarain-Herzberg A, Gangiotensinuly PK, Dhalla NS. Captopril treatment improves the sarcoplasmic reticular calcium transport in heart failure due to myocardial infarction. $J$ of $\mathrm{Mol} \mathrm{Cell}$ Cardiol. 1999;31:1663-1672.

23. Shao Q, Takeda N, Temsah R, Dhalla NS. Prevention of hemodynamic changes due to myocardial infarction by early treatment with imidapril. Cardiovasc Pathobiol. 1996;1:180-186.

24. Pitt B. Importance of angiotensin-converting enzyme inhibitors in myocardial infarction and congestive heart failure: impliocations for clinical practice. Cardiology. 1995;86 Suppl 1:41-45.

25. Burnier M. Angiotensin II type 1 receptor blockers. Circulation. 2001; 103:904-912.

26. Thurmann PA, Colette D. Angiotensin II type 1 receptor antagonists in chronic heart failure. Expert Opin Invest Drugs. 2002;11:2705-2716.

27. Burnier M, Brunner HR. Renal effects of angiotensin II receptor blockade and angiotensin-converting enzyme inhibition in healthy subjects. Exp Nephrol. 1996;4 Suppl 1:41-46.

28. Chiu AT, McCall DE, Prize WA, et al. Nonpeptide angiotensin II receptor antagonists. VII. Cellular and biochemical pharmacology of DuP 753, an orally active antihypertensive agent. J Pharmacol Exp Ther. 1990;252:711-718.

29. Sirajy H. Angiotensin II receptor blockers: review of the binding characteristics. Am J Cardiol. 1999;84:3S-8S

30. Milavetz JJ, Raya TE, Johnson CS, Morkin E, Goldman S. Survival after myocardial infarction in rats: captopril versus losartan. $J$ Am Coll Cardiol. 1996;27:714-719.

31. Shao Q, Saward L, Zahradka P, Dhalla NS. $\mathrm{Ca}^{2+}$ mobilization in adult rat cardiomyocytes by Angiotensin type 1 and 2 recceptors. Biochem Pharmacol. 1998;55:1413-1418.

32. Kumar S, MacGregor JS, Gupta M, et al. Effect of selective angiotensin II receptor antagonism and angiotensin-converting enzyme inhibition on the coronary vasculature in vivo. Intravascular two-dimensional and Doppler ultrasound studies. Circulation. 1993;87:931-938.
33. Sweet CS, Rucinska EJ. Losartan in heart failure: preclinical experiences and initial clinical outcomes. Eur Heart J. 1994;15 Suppl D:139-144.

34. Liu X, Lukasova M, Zubakova R, Lewicka S, Hilgenfeldt U. Kallidinlike peptide mediates the cardioprotective effect of the ACE inhibitor captopril against ischemic reperfusion injury of rat heart. Br J Pharmacol. 2006;148:825-832.

35. Schriefer JA, Broudy EP, Hassen AH. Inhibitors of bradykinininactivating enzymes decrease myocardial ischemia/reperfusion injury following 3 and 7 days of reperfusion. J Pharmacol Exp Ther. 2001; 298:970-975.

36. GauthamanK,MaulikM,KumariR,Manchanda SC,DindaAK,MaulikSK. Effect of chronic treatment with bark of Terminalia Arjuna, a study on the isolated ischemic reperfused rat heart. J Ethnopharmacol. 2001;75: 197-201.

37. Baxter GF, Ebrahim Z. Role of bradykinin in preconditioning and protection of the ischemic myocardium. Br J Pharmacol. 2002;135: 843-854.

38. Anderson B, Khaper N, Dhalla AK, Singal PK. Anti-free radical mechanisms in captopril protection against reperfusion injury in isolated rat hearts. Can J Cardiol. 1996;12:1099-1104.

39. Yusuf S, Sleight P, Pogue J, Bosch J, Davies R, Dagenais G. Effects of an Angiotensin converting enzyme inhibitor, ramipril, on cardiovascular events in high risk patients. N Eng J Med. 2000;342:145-153.

40. Cargnoni A, Comini L, Bernocchi P, et al. Role of bradykinin and eNOS in the anti-ischemic effect of trandolapril. Br J Pharmacol. 2001;133: 145-153.

41. Kloner RA, Bahiru E. A comparative literature review exploring hypertension drugs that lower target organ damage above and beyond reducing blood pressure based on research studies between 1992 and 2006. Curr Hypertens Revs. 2008;4:167-176.

42. Kaplan NM. Combination therapy for hypertension. Cardiology. 2009; 6:270-271.

43. Rosendorff C, Black HR, Cannon CP, et al. Treatment of hypertension in the prevention and management of ischemic heart disease: a scientific statement from the American Heart Association Council for high blood pressure research and the councils on clinical cardiology and epidemiology and prevention. Circulation. 2007;115:2761-2788.

44. Jamerson K, Weber MA, Balkris GL, et al. Benazepril plus amlodipine or hydrochlorothiazide for hypertension in high risk patients. $N$ Engl $J$ Med. 2008;359:2417-2428.

45. Spinale FG, Mukherjee R, Iannini JP, et al. Modulation of the renninAngiotensin pathway through enzyme inhibition and specific recptor blockade in pacing-induced heart failure: II. Effects on myocytes contractile processes. Circulation. 1997;96:2397-2406.

46. Spinale FG, Mukherjee R, Iannini JP, et al. Modulation of the renninAngiotensin pathway through enzyme inhibition and specific receptor blockade in pacing-induced heart failure: I. Effects on left ventricular performance and neurohormonal systems. Circulation. 1997;96: 2385-2396.

47. Azizi M, Chatellier G, Guyene TT, Murieta-Geoffroy D, Menard J. Additive effects of combined angiotensin-converting enzyme inhibition and angiotensin II antagonism on blood pressure and renin release in sodium-depleted normotensives. Circulation. 1995;92:825-834.

48. Mogensen CE, Neldam S, Tikkanen I, et al. Randomised controlled trial of dual blockade of renin-Angiotensin system in patients with hypertension, microalbuminuria, and non-insulin dependent diabetes: the Candesartan and Lisinopril Microalbuminuria (CALM) study. BMJ. 2000;321:1440-1444.

49. Nakao N, Yoshimura A, Morita H, Takada M, Kayano T, Ideura T. Combination treatment of Angiotensin-II receptor blocker and Angiotensin-converting-enzyme inhibitor in non-diabetic renal disease (COOPERATE): a randomised controlled trial. Lancet. 2003;361:117-124

50. Mazzolai L, Maillard M, Rossat J, Nussberger J, Brunner HR, Burnier M. Angiotensin II receptor blockade in normotensive subjects: A direct comparison of three AT1 receptor antagonists. Hypertension. 1999;33:850-855.

51. Weidenbach R, Schulz R, Gres P, Behrends M, Post H, Heusch G. Enhanced reduction of myocardial infarct size by combined ACE inhibition and $\mathrm{AT}_{1}$-receptor antagonism. Br J Pharmacol. 2000;131: $138-144$. 
52. Werner CM, Bohm M. The Therapeutic role of RAS blockade in chronic heart failure. Ther Adv Cardiovasc Dis. 2008;2:167-177.

53. Ozaydin M, Turker Y, Peker O, et al. Association between the use of non-antiarrhythmic drugs and postoperative atrial fibrillation. Int $J$ Cardiol. 2009 Mar 10. [Epub ahead of print].

54. Elahi MM, Flatman S, Matata BM. Tracing the origins of postoperative atrial fibrillation: the concept of oxidative stress-mediated myocardial injury phenomenon. Eur J Cardiovasc Prev Rehabil. 2008;15(6): 735-741.

55. Spinar J, Vitovec J, Soucek M, Dusek L, Pavlik T; CORD investigators. CORD: COmparison of Recommended Doses of ACE inhibitors and angiotensin II receptor blockers. Vnitr Lek. 2009;55:481-488.

56. Cravedi P, Ruggenenti P, Remuzzi G. Intensified inhibition of reninangiotensin system: a way to improve renal protection? Curr Hypertens Rep. 2009;11(2):118-124.

57. Palardy M, Ducharme A, O'Meara E. Inhibiting the renin-angiotensin system with ACE Inhibitors or ARBs after MI. Curr Heart Fail Rep. 2007;4(4):190-197.

58. Thomas GN, Tomlinson B. Prevention of macrovascular disease in type 2 diabetic patients: blockade of the renin-angiotensin-aldosterone system. Curr Diabetes Rev. 2008;4:63-78.

59. Tokmakova M, Solomon SD. Inhibiting the renin-angiotensin system in myocardial infarction and heart failure: lessons from SAVE, VALIANT and CHARM, and other clinical trials. Curr Opin Cardiol. 2006; 21:268-272.

60. Brown JD, Plutzky J. Peroxisome proliferator-activated receptors as transcriptional nodal points and therapeutic targets. Circulation. 2007;115:518-533.

61. Lonn E, Shaikholeslami R, Yi Q, et al. Effects of ramipril on left ventricular mass and function in cardiovascular patients with controlled blood pressure and with preserved left ventricular ejection fraction: a substudy of the heart outcomes prevention evaluation (HOPE) Trial. $J$ Am Coll Cardiol. 2004;43:2200-2206.

62. Dahlof B, Devereux RB, Kjeldsen SE, et al; LIFE Study Group. Cardiovascular morbidity and mortality in the Losartan Intervention For Endpoint reduction in hypertension (LIFE) study. Lancet. 2002;359:995-1003.

63. Dickstein K, Kjekshus J. Effects of losartan and captopril on mortality and morbidity in high-risk patients after acute myocardial infarction: the OPTIMAAL randomized trial. Optimal trial in myocardial infarction with angiotensin II antagonist losartan. Lancet. 2002;360:752-760.

64. Friedrich EB, Teo KK, Bohm M. ACE inhibition in secondary prevention: are the results controversial? Clin Res Cardiol. 2006;95:61-67.

65. Yusuf S, Sleight P, Pogue J, Bosch J, Davies R, Dagenais G. Effects of an angiotensin-converting-enzyme inhibitor, ramipril, on cardiovascular events in high-risk patients. The heart outcomes prevention evaluation study investigators. N Engl J Med. 2000;342:145-153.

66. Fox KM. Efficacy of perindopril in reduction of cardiovascular events among patients with stable coronary artery disease: randomised, doubleblind, placebo-controlled, multicentre trial (the EUROPA study). Lancet. 2003;362:782-788.

67. Braunwald E, Domanski MJ, Fowler SE, et al; PEACE Trial Investigators. Angiotensin-converting-enzyme inhibition in stable coronary artery disease. $N$ Engl J Med. 2004;351:2058-2068.
68. Pitt B, O’Neill B, Feldman R, et al. The QUinapril Ischemic Event Trial (QUIET): evaluation of chronic ACE inhibitor therapy in patients with ischemic heart disease and preserved left ventricular function. $\mathrm{Am} \mathrm{J}$ Cardiol. 2001;87:1058-1063.

69. Scaglione R, Argano C, Di Chiara T, et al. Effect of dual blockade of renin-angiotensin system on TGFbetal and left ventricular structure and function in hypertensive patients. J Hum Hypertens. 2007;s21: 307-315.

70. The CONSENSUS Trial Study Group. Effects of enalapril on mortality in severe congestive heart failure. Results of the cooperative north scandinavian enalapril survival study (CONSENSUS). $N$ Engl $J$ Med. 1987;316:1429-1435.

71. McKelvie RS, Yusuf S, Pericak D, et al. Comparison of candesartan, enalapril, and their combination in congestive heart failure: randomized evaluation of strategies for left ventricular dysfunction (RESOLVD) pilot study. The RESOLVD Pilot Study Investigators. Circulation. 1999;100: 1056-1064.

72. Pitt B, O’Neill B, Feldman R, et al. The quinapril ischemic event trial (QUIET): evaluation of chronic ACE inhibitor therapy in patients with ischemic heart disease and preserved left ventricular function. $\mathrm{Am} \mathrm{J}$ Cardiol. 2000;87:1058-1063.

73. Hoppe UC. Treatment of heart failure with ACE inhibitors and betablockers: what is next? AT1-receptor antagonists? Clin Res Cardiol. 2007;96:196-198.

74. Doulton TW, He FJ, MacGregor GA. Systematic review of combined angiotensin-converting enzyme inhibition and angiotensin receptor blockade in hypertension. Hypertension. 2005; 45:880-886.

75. Sleight P, Jacobsen A, Heroys J, Ralph A, Rees T, Shaw M. No HOPE without proof: Do ARBs meet the standard for cardiovascular protection? Medscape J Med. 2008;10(Suppl):S6.

76. Teo K, Yusuf S, Sleight P, et al. Rationale, design, and baseline characteristics of 2 large, simple, randomized trials evaluating telmisartan, ramipril, and their combination in high-risk patients: the Ongoing Telmisartan Alone and in Combination with Ramipril Global Endpoint Trial/Telmisartan Randomized Assessment Study in ACE Intolerant Subjects with Cardiovascular Disease (ONTARGET/TRANSCEND) trials. Am Heart J. 2004;148:52-61.

77. Bissessor N, White H. Valsartan in the treatment of heart failure or left ventricular dysfunction after myocardial infarction. Vasc Health Risk Manag. 2007;3(4):425-430.

78. Van der Horst I, Voors AA, van Veldhuisen DJ. Treatment of heart failure with ACE inhibitors and beta-blockers: what is next? Aldosterone receptor antagonists? Clin Res Cardiol. 2007;96:193-195.

79. Dhalla NS, Guo X. Beneficial effects of renin angiotensin system blockade in myocardial infarction. In: Gupta S (ed) Pharmacology and Therapeutics in the New millennium. Gupta S. (editor). New Delhi, India: Narosa Publishing House; 2001:60.

\section{Publish your work in this journal}

Open Access Emergency Medicine is an international, peer-reviewed, open access journal publishing original research, reports, editorials, reviews and commentaries on all aspects of emergency medicine. The manuscript management system is completely online and includes a very quick and fair peer-review system, which is all easy to use.

\section{Dovepress}

Visit http://www.dovepress.com/testimonials.php to read real quotes from published authors. 